\title{
Numerical analysis of impact fracture of laminated glass - a review
}

\begin{abstract}
Laminated glass (LG) is a sandwiched composite structure, composed of two pieces of outer glass layers and one or more pieces of the polymer films (interlayer) sandwiched inbetween of the glasses. Impact strength of LG is the most significant mechanical property due to architectural, glazing, automotive, and decorative applications. Recently, a good no of numerical simulations are reported for impact failure analysis of LG. The purpose of this mini review is discussion on numerical algorithms for modeling the principal damage pattern and glass-ply cracking in LG. It is observed from this review that quantitative works need to be carried out to validate the capacity of numerical algorithms in the impact failure analysis of the LG.
\end{abstract}

Keywords: architectural glass, EVA, laminated composites, PVB, wind shield
Volume 3 Issue 6 - 2017

\author{
Ajitanshu Vedrtnam, SJ Pawar \\ Department of Applied Mechanics, Motilal Nehru National \\ Institute of Technology Allahabad, India
}

\begin{abstract}
Correspondence: Ajitanshu Vedrtnam, Allahabad, Department of Applied Mechanics, Motilal Nehru National Institute of Technology Allahabad UP, India-2 I I 004, Fax no: 053-222-7| 2-00, Email ajitanshu.m@invertis.org
\end{abstract}

Received: May 09, 2017 | Published: December 18, 2017
Abbreviations: LG, laminated glass; DE, discrete element; FE, finite element; DEM, discrete element method

\section{Introduction}

LG comprises of two layers of glass and one or more layers of polymer film (inter-layer) that is sandwiched in-between by putting under heat and pressure. Inter-layer improves mechanical properties like impact strength, fracture toughness and failure mode of LG. ${ }^{1}$ As area of impact increases there is possibility of increment of the impact resistance. The fracture of LG is designed so as to the Inter layer keeps together broken pieces that can possibly cause dangerous incidents or accidents. The LG dampens the energy of impact and improves the brittle fracture behavior when compared with monolithic glass. This functionality forces designers to use LG wherever there may be an injury risk due to glass fracture. A good no of theoretical studies, ${ }^{2-8}$ experimental studies ${ }^{9-22}$ numerical studies, ${ }^{10,23-45}$ LS DYNA and ABAQUS based studies ${ }^{18-36}$ and discrete element (DE)/finite element (FE) based studies are reported to analyze impact failure of LG. The present work is focused on reviewing the numerical algorithms used to model the impact fracture of LG.

\section{Literature review}

Impact failure analysis of LG is commonly done experimentally followed by numerical simulations. The failure processes of LG due to impact analyzed during pre-failure, failure and post-failure stages. Analytical models are commonly employed to describe the mechanical performance of LG for the pre and post-failure stages. ${ }^{46-50}$ The postfailure response of LG is also explained by numerical simulations ${ }^{51,52}$ and experiments. The literature frequently focuses on the principal damage pattern and glass-ply cracking. The commonly used numerical algorithms sighted in the literature for impact simulation are element deletion method (EDM), the continuum damage mechanics (CDM), the discrete element method (DEM), the combined discrete/finite element methods (DEM/FEMs), the extended finite element method
(XFEM) and the cohesive zone model (CZM). The adhesion modeling is usually simulated using shared node method, the penalty-based methods and the intrinsic CZM. The EDM consist of removal of the mass of elements from the global mass matrix or set the stress of elements to zero, so as to represent the failure of these elements (used in LS-DYNA). This method is used..$^{53,54} \mathrm{Xu}$ et al. ${ }^{55}$ developed a numerical model on LG-PVB subjected to low-speed impact. The LG was impacted by a standard head form impact or at the speed of $8 \mathrm{~m} / \mathrm{s}$ based on the LS-DYNA platform. The results were compared with the dynamic experiments of LG-PVB under head form impact to find the most accurate FE model. Pyttel et al. ${ }^{56}$ have found failure benchmark norm for the LG when subjected to impact loading. It has been stated that a hazardous energy threshold should be reached during a finite expanse before failure took place. To regulate the norm and estimate its precision, various tests with curved and plain samples of LG were performed. The comparison between simulated and measured result showed that the norm works sound. ${ }^{56}$ The CDM includes depiction of the damage effect of a material by its stress-strain behavior. ${ }^{57}$ Sun et al. ${ }^{58,59}$ constituted a model considering the contribution of damage to the constitutive law for the modeling of glass-ply cracking. Zhao et al. ${ }^{60}$ used this model to simulate the damage of LG panel under the impact loading. The web-shaped, star-shaped and shear damage fracture pattern were observed during simulation. Sun et al..$^{58}$ also used this model to numerically find the windshield design parameters (thickness and curvature) on its stone-impact resistance.$^{61}$ The DEM includes discretizing the solving domain into a cluster of discrete elements (DEs), and describe the movements of DEs by Newton's second law. The interactions between DEs are usually handled by using contact algorithms. Zang et al. ${ }^{62}$ used $3 \mathrm{D}$ discrete element method to study the impact fracture of LG. The glass and PVB of LG planes were discretizing to uniform rigid spherical elements (Figure 1). This investigation showed that the accuracy of the 3D model and numerical analysis were significantly validated in the elastic range in comparison to FEM. ${ }^{62}$ The combined discrete and FE methods overcome the inability of DEM to describe the large deformation 
behavior of the inter-layer. Therefore, as shown in Figure 2, Lei et al. ${ }^{62}$ proposed a DEM/FEM based on a penalty method. As shown in Figure 2 the solving domain is decomposed into two parts ( $\mathrm{Ua}$ and $\mathrm{Ub}$ ) with a common interface. Sab Sua Ssa, Sub and Ssb are correspondingly the displacement and traction boundaries of sub-domain Ua and Ub. Fig. 17 shows the glass plies discretized into a series of DEs and the inter-layer discretized into a series of FEs. ${ }^{63}$

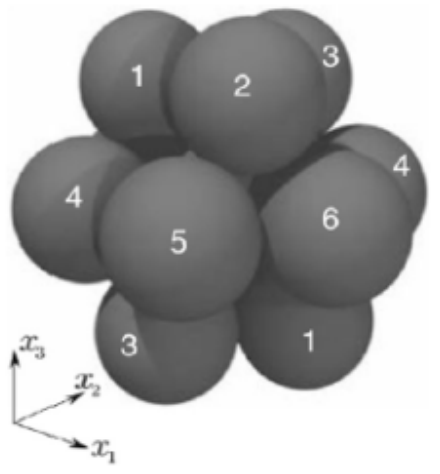

(a) hexagonal layout

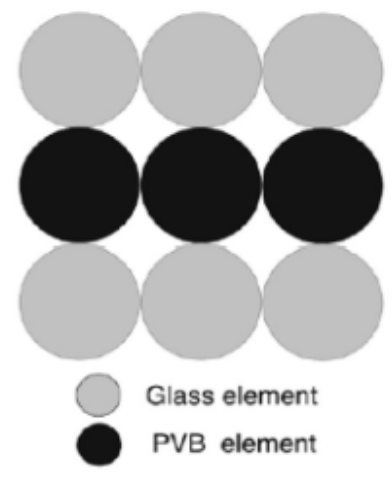

(b) square layout
Figure I DE models for LG. ${ }^{62}$

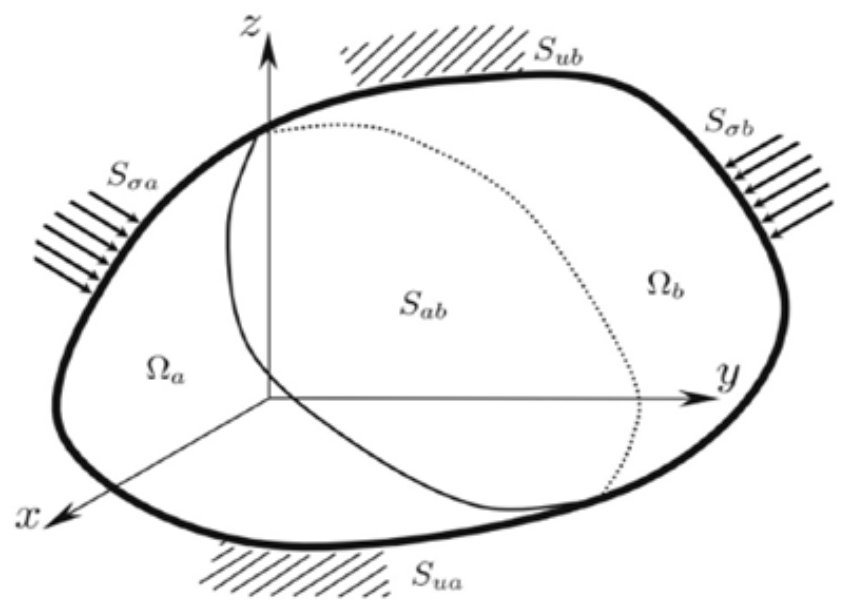

Figure 2 Schematic diagram of the DEM/FEM proposed. ${ }^{63}$

$\mathrm{Xu} \& \mathrm{Zang}^{35}$ developed four-point combined FE/discrete element (DE) algorithm for the brittle fracture study of the LG. In this study, the penalty method was applied to calculate the interface force between two sub domains, the FE and the DE sub domains. It was found that on comparing the impact fracture tests with the simulation results, there were changes in the amount of the cracks of upper and lower glass, but the location of cracks and propagation paths are similar to the investigation outcomes. Hence, it is concluded that the theory stated was effective to forecast some macroscopic fracture features such as the crack location and the crack diffusion. ${ }^{63}$ Four algorithms were suggested to combine DEs and FEs (Nodel combine algorithm, ${ }^{63}$ surface-center algorithm, ${ }^{64}$ freely combined algorithm ${ }^{65}$ and four-point combined algorithm) ${ }^{66}$ as shown in Figure 3. The XFEM includes cracking simulation by extending the shape functions of the conventional FEM with extra enriched functions in the cracking area. ${ }^{67-72}$ The cracks can be represented independently of FE meshes and crack growth modeling doesn't require re-meshing in XFEM. Jaśkowiez ${ }^{73}$ performed numerical modeling for delamination in LG by XFEM. XFEM was used to input discontinuity to the approximation field. The developed model was found suitable for three-dimensional delamination analysis. ${ }^{73}$ The CZMs includes idealizing fracture as a gradual process of separation in the small region ahead of the crack front. CZM is governed by a phenomenological traction-separation law and used frequently for performing failure analysis. ${ }^{74-77} \mathrm{Chen}$ et al. ${ }^{16}$ simulated the impact fracture of a LG under drop-weight impact. The common glass-ply crack patterns were captured in the simulations with a special designed FE meshes (Figure 4). It is reflected from the Figure 4 that the propagations of radial cracks are somewhat constrained in the areas away from the impact point when brick elements are adopted for the LG model. ${ }^{77}$

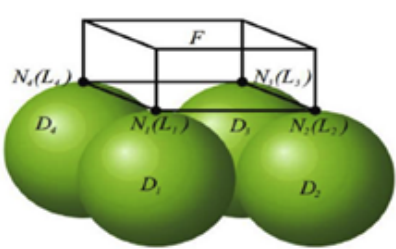

(a) nodal combined algorithm

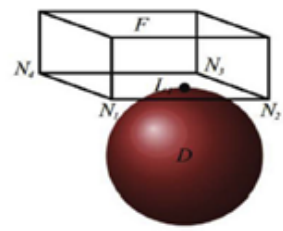

(c) freely combined algorithm

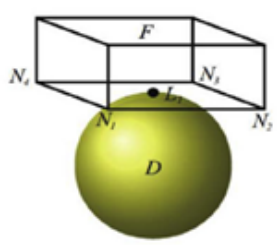

(b) surface-center combined algorithm

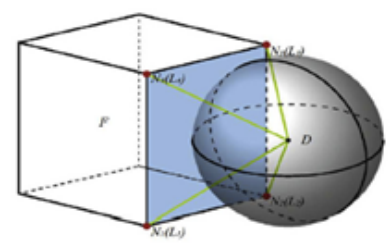

(d) four-point combined algorithm
Figure 3 Four DEM/FEMs proposed. ${ }^{63-66}$
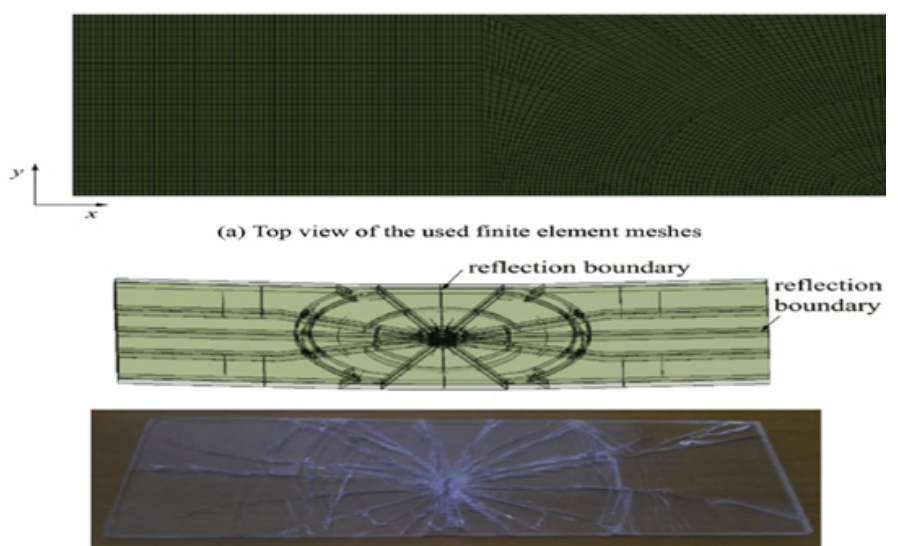
(b) Fracture patterns. Top one is the simulation result; and the bottom one
is the experiment result.

Figure 4 The impact fracture patterns of a LG plate by using the extrinsic CZM. $^{78}$

\section{Conclusion}

It is clear from the review that a lot of research work is done in the field of laminated composite glass that includes analytical models, experimental studies, and software simulations. The principal damage pattern, glass-ply cracking is analyzed using six numerical algorithms (EDM, CDM, DEM, DEM/FEMs, XFEM and CZM). The DEM/ FEMs, XFEM and CZM used for small-size LG specimens for the glass-ply cracking modeling whereas EDM can be applied to the impact failure analysis of bigger size of LG. Further, it is suggested 
that quantitative works should to be carried out to validate the capacity of numerical algorithms.

\section{Funding}

None.

\section{Acknowledgments}

None.

\section{Conflicts of interest}

The author declares that there is no conflict of interest.

\section{References}

1. Morgan WL. Manufacture and Characteristics of Laminated Glass Industrial and engineering chemistry. 1931;23(5):505-508.

2. Naumenko K, Eremeyev VA. A layer-wise theory for laminated glass and photovoltaic panels. Composite Structures. 2014;112:283-291.

3. Eisenträger J, Naumenko K, Altenbach H, et al. A user-defined finite element for laminated glass panels and photovoltaic modules based on a layer-wise theory. Composite Structures. 2015;133(1):265-277.

4. Foraboschi P. Analytical model for laminated-glass plate. Composites Part B: Engineering. 2012;43(5):2094-2106.

5. Galuppi L, Royer-Carfagni GF. Effective thickness of laminated glass beams: new expression via a variational approach. Engineering Structures. 2012;38:53-67.

6. Foraboschi P. Hybrid laminated-glass plate: design and assessment Composite Structures. 2013;106:250-263.

7. Focacci F, Foraboschi F, De Stefano M. Composite beam generally connected: Analytical model. Composite Structures. 2015;133:1237-1248.

8. Overend M, Butchart C, Lambert $\mathrm{H}$, et al. The mechanical performance of laminated hybrid-glass units. Composite Structures. 2014;110:163-173.

9. Bennison SJ, Jagota A, Smith CA. Fracture of glass/poly (vinyl butyral) (Butacite) laminates in biaxial flexure. Journal of the American Ceramic Society. 1999;82(7):1761-1770.

10. Larcher M, Solomos G, Casadei F, et al. Experimental and numerical investigations of laminated glass subjected to blast loading. International Journal of Impact Engineering. 2012;39(1):42-50.

11. Xu J, Li Y, Liu B, et al. Experimental study on mechanical behavior of PVB laminated glass under quasi-static and dynamic loadings. Composites Part B: Engineering. 2011;42(2):302-308.

12. Belis J, Depauw J, Callewaert D, et al. Failure mechanisms and residual capacity of annealed glass/SGP laminated beams at room temperature. Engineering Failure Analysis. 2009;16(6):1866-1875.

13. Biolzi L, Cattaneo S, Rosati G. Progressive damage and fracture of laminated glass beams. Construction and Building Materials. 2010;24(4):577-584.

14. Xu J, Sun Y, Liu B, et al. Experimental and macroscopic investigation of dynamic crack patterns in PVB laminated glass sheets subject to lightweight impact. Engineering Failure Analysis. 2011;18:1605-1612.

15. Chen J, Xu J, Liu B, et al. Quantity Effect of Radial Cracks on the Cracking Propagation Behavior and the Crack Morphology. PLoS ONE. 2014;9(7):e98196.

16. Chen J, Xu J, Yao X, et al. Experimental investigation on the radial and circular crack propagation of PVB laminated glass subject to dynamic outof-plane loading. Engineering Fracture Mechanics. 2013;112-113:26-40.
17. Chen J, Xu J, Yao X, et al. Different driving mechanisms of in-plane cracking on two brittle layers of laminated glass, International Journal of Impact Engineering. 2004;69:80-85.

18. Norville HS, King KW, Jason LS. Behavior and strength of laminated Glass. Journal of Engineering Mechanics. 1998;124(1):46-53.

19. Weinad J, Dharani L. Response of laminated architectural glazing subject to blast loading. International Journal of Impact engineering. 2006;32(12):2032-2047.

20. Larcher M, George SC Folco, Norbet G. Experimental and numerical investigations of laminated glass subject to blast loading. International Journal of Impact engineering. 2012;39(1):42-50.

21. Seshadri M, Bennison SJ, Jagoda A, et al. Mechanical responce of cracked laminated plates. Journal of Acta Materialia. 2002;50(18):4477-4490.

22. Zhang X, Hao H, Ma G. Laboratory test and numerical simulation of laminated glass window vulnerability to debris impact. International Journal of Impact Engineering. 2013;55:49-62.

23. Del Linz P, Hooper P, Arora H, et al. Reaction forces of laminated glass windows subject to blast loads. Composite Structures. 2015;131:193-206.

24. Du Bois P, Kolling S, Fassnacht W. Modelling of safety glass for crash simulation. Computational Materials Science. 2003;28(3-4):675-683.

25. Hooper P, Sukhram R, Blackman B, et al. On the blast resistance of laminated glass. International Journal of Solids and Structures. 2012;49(6):899-918.

26. Timmel M, Kolling S, Osterrieder P, et al. A finite element model for impact simulation with laminated glass. International Journal of Impact Engineering. 2007;34(8):1465-1478.

27. Hidallana-Gamage HD, Thambiratnam DP, Perera NJ. Failure analysis of laminated glass panels subjected to blast loads. Engineering Failure Analysis. 2014;36:14-29.

28. Pyttel T, Liebertz H, Cai J. Failure criterion for laminated glass under impact loading and its application in finite element simulation. International Journal of Impact Engineering. 2011;38(4):252-263.

29. Peng Y, Yang J, Deck C, et al. Finite element modeling of crash test behavior for windshield laminated glass. International Journal of Impact Engineering. 2013;57:27-35.

30. Zhang X, Hao H, Ma G. Laboratory test and numerical simulation of laminated glass window vulnerability to debris impact. International Journal of Impact Engineering. 2013;55:49-62.

31. Zhang X, Hao H, Ma G. Parametric study of laminated glass window response to blast loads. Engineering Structures. 2013;56:1707-1717.

32. Zhao S, Dharani LR, Chai L, et al. Analysis of damage in laminated automotive glazing subjected to simulated head impact. Engineering Failure Analysis. 2006;13(4):582-597.

33. Xu J, Li Y. Study of damage in windshield glazing subject to impact by a pedestrian's head, Proceedings of the Institution of Mechanical Engineers, Part D. Journal of Automobile Engineering. 2009;223:77-84.

34. Lei Z, Zang M. An approach to combining 3D discrete and finite element methods based on penalty function method. Computational Mechanics. 2010;46(4):609-619.

35. Xu W, Zang M. Four-point combined DE/FE algorithm for brittle fracture analysis of laminated glass. International Journal of Solids and Structures. 2014;51(10):1890-1900.

36. $\mathrm{Xu} \mathrm{W}$, Zang $\mathrm{M}$, GaoW. Adaptive combined DE/FE algorithm for brittle fracture of plane stress problems. Computational Mechanics. 2014;54(2):535-546. 
37. Gao W, M Zang. The simulation of laminated glass beam impact problem by developing fracture model of spherical DEM. Engineering Analysis with Boundary Elements. 2014;42:2-7.

38. Xu J, Li Y, Chen X, et al. Characteristics of windshield cracking upon low-speed impact: Numerical simulation based on the extended finite element method. Computational Materials Science. 2010;48(2):582-588.

39. Chen S, Zang M, Xu W. A three-dimensional computational framework for impact fracture analysis of automotive laminated glass. Computer Methods in Applied Mechanics and Engineering. 2015;294:72-99.

40. Hidallana-Gamage $\mathrm{H}$, Thambiratnam $\mathrm{D}$, Perera $\mathrm{N}$. Influence of interlayer properties on the blast performance of laminated glass panels. Construction and Building Materials. 2015;98:502-518.

41. Hidallana-Gamage HD, Thambiratnam DP, Perera NJ. Numerical modelling and analysis of the blast performance of laminated glass panels and the influence of material parameters. Engineering Failure Analysis. 2014;45:65-84

42. Timmela M, Kollingb S, Osterriederc P, et al. A finite element model for impact simulation with laminated glass. International Journal of Impact Engineering. 2007;34(8):1465-1478.

43. PA Du Bois, Fassnacht W, Kolling S. Material modeling with LS-DYNA for crashworthiness analysis, 8 Germany: LS-DYNA Forum. Bad Mergentheim. 2002;2:1-55.

44. Repetto E, Radovitzky R, Ortiz M. Finite element simulation of dynamic fracture and fragmentation of glass rods. Computer Methods in Applied Mechanics and Engineering. 2000;183(1-2):3-14.

45. Pyttel T, Liebertz H, Cai J. Failure criterion for laminated glass under impact loading and its application in finite element simulation. International Journal of Impact Engineering. 2011;38(4):252-263. Aenlle ML, Pelayo F. Dynamic effective thickness in laminated-glass beams and plates. Composites: Part B Engineering. 2014;67:332-347.

46. Del Linz P, Liang X, Hooper P, et al. An analytical solution for precrack behaviour of laminated glass under blast loading. Compos Struct. 2016;144:156-164.

47. Galuppi L, Royer-Carfagni G. A homogenized model for the post-breakage tensile behavior of laminated glass. Compos Struct. 2016;154:600-615.

48. Dural E. Analysis of delaminated glass beams subjected to different boundary conditions. Compos Part B Eng. 2016;101:132-146.

49. Wu P, Zhou D, Liu W, et al. 3-D exact solution of two-layer plate bonded by a viscoelastic interlayer with memory effect. Compos Struct. 2017;164:291-303

50. Focacci F, Foraboschi P, De Stefano M. Composite beam generally connected: analytical model. Compos Struct. 2015;133:1237-1248.

51. Pelfrene J, Kuntsche J, Van Dam S, et al. Critical assessment of the postbreakage performance of blast loaded laminated glazing: experiments and simulations. Int J Impact Eng. 2016;88:61-71.

52. Baraldi D, Cecchi A, Foraboschi P. Broken tempered laminated glass: nonlinear discrete element modeling. Compos Struct. 2016;140:278-295.

53. Song JH, Wang H, Belytschko T. A comparative study on finite element methods for dynamic fracture. Comput Mech. 2008;42(2):239-250.

54. Hallquist JO. LS-DYNA theory manual. Livermore Software Technology Corporation, USA; 2006.

55. Xu X, Liu BH, Li WY, et al. A numerical model on PVB laminated windshield subjected to head form low-speed impact. Journal of physics: conference series IOP Publishing. 2013;451(1):1-5.

56. Pickett AK, Pyttel T, Payen F, et al. Failure prediction for advanced crashworthiness of transportation vehicles. Intl J of Impact Engineering. 2004;30(7):853-872.
57. Kachanov L. Introduction to continuum damage mechanics. Springer Science \& Business Media. 2013.

58. Sun X, Khaleel MA. Modeling of glass fracture damage using continuum damage mechanics-static spherical indentation. Int $J$ Damage Mech. 2004; $13: 263-285$.

59. Sun X, Khaleel MA, Davies RW. Modeling of stone-impact resistance of monolithic glass ply using continuum damage mechanics. Int J Damage Mech. 2005;14:165-178.

60. Zhao S, Dharani LR, Chai L, et al. Analysis of damage in laminated automotive glazing subjected to simulated head impact. Eng Fail Anal. 2006;13(4):582-597.

61. Sun X, Khaleel MA. Effects of different design parameters on the stone impact resistance of automotive windshields. Proc Institution Mech Eng Part D J Automob Eng. 2005;219:1059-1067.

62. Zang MY, Lei Z, Wang SF. Investigation of impact fracture behavior of automobile laminated glass by $3 \mathrm{D}$ discrete element method. Springer Verlag. 2007;41(1):73-83.

63. Lei Z, Zang M. An approach to combining 3D discrete and finite element methods based on penalty function method. Comput Mech. 2010;46(4):609-619.

64. $\mathrm{Xu} \mathrm{W}$, Zang M. Four-point combined DE/FE algorithm for brittle fracture analysis of laminated glass. Int J Solids Struct. 2014;51(10):1890-1900.

65. Yu J, Liu X, Zang M. Impacting response emulation of front windshield based on DEM/FEM coupling. J Hunan Univ Nat Sci. 2010;37:126-139.

66. Gao W, Zang M, Xu W. An approach to freely combining 3D discrete and finite element methods. Int J Comput Methods. 2014;11:135-151.

67. Dolbow J, Belytschko T. A finite element method for crack growth without remeshing. Int J Numer Methods Eng.1999;46:131-150.

68. Moes N, Belytschko T. Extended finite element method for cohesive crack growth. Eng Fract Mech. 2000;69(7):813-833.

69. Sukumar N, Moes N, Moran B, et al. Extended finite element method for three-dimensional crack modelling. Int $\mathrm{J}$ Numer Methods Eng. 2000;48(11):1549-1570.

70. Fries TP, Belytschko T. The extended/generalized finite element method: an overview of the method and its applications. Int J Numer Methods Eng. 2010;84(3):253-304.

71. Nian G, Shan Y, Xu Q, et al. Failure analysis of syntactic foams: a computational model with cohesive law and XFEM. Compos Part B Eng. 2016;89:18-26.

72. Benvenuti E, Orlando N, Ferretti D, et al. A new 3D experimentally consistent XFEM to simulate delamination in FRP-reinforced concrete. Compos Part B Eng. 2016;91:346-360.

73. Jaśkowiec J. Numerical Modeling Mechanical Delamination in Laminated Glass by XFEM. Scientific-Technical Conference on Material Problems in Civil Engineering MATBUD'2015. Procedia Engineering. 2015;108:293-300

74. Xu X, Needleman A. Numerical simulations of fast crack growth in brittle solids. J Mech Phys Solids. 1994;42(9):1397-1434.

75. Fernandez-Caenadas LM, Ivana I, Sanchez-Saez S. Influence of the cohesive law shape on the composite adhesively-bonded patch repair behaviour. Compos Part B Eng. 2016;91:414-421.

76. Ribeiro F, Campilho R, Carbas R,et al. Strength and damage growth in composite bonded joints with defects. Compos Part B Eng. 2016;100:91-100.

77. Tu W, Pindera MJ. Damage evolution in cross-ply laminates revisited via cohesive zone model and finite-volume homogenization. Compos Part B Eng. 2016;86:40-60. 